\title{
Changes in employer-sponsored private health insurance among retirees in Ontario: a cross-sectional study
}

\author{
Fiona K.I. Chan MSc, Kimberlyn McGrail PhD, Sumit R. Majumdar MD MPH, Michael R. Law PhD
}

Abstract

Background: Employer-sponsored health insurance, particularly for retirees with limited incomes, plays a major funding role in Canadian health care, including prescription drugs and dental services. We aimed to investigate the changes in retiree health insurance availability over time.

Methods: We performed a secondary analysis of data from the 2005 and 2013-2014 cycles of the Canadian Community Health Survey using multivariate logistic regression to study changes in retiree coverage availability over time in Ontario. We estimated the adjusted odds ratios of having employer coverage for likely retirees (people over age 65 yr who reported not working and those over age $75 \mathrm{yr}$ ), adjusting for a number of potential confounders. Sensitivity analysis was also performed for coverage of different treatments separately.

Results: The response rate was $76 \%$ for the 2005 cycle and $66 \%$ for $2013-2014$ for the entire survey. The characteristics of respondents in the 2 survey cycles were similar, except respondents in 2013-2014 were wealthier. In our adjusted model, respondents in 2013-2014 had lower odds of reporting retiree coverage than respondents in 2005 (adjusted odds ratio 0.87; 95\% confidence interval $0.77-0.99)$. This represents an absolute reduction in the probability of receiving retiree coverage of up to $3.4 \%$.

Interpretation: Our analysis suggests that the rate of retiree health insurance has declined for Canadians with similar characteristics over the past decade. As we know insurance coverage has a strong association with use of treatments such as prescription drugs and dental care, this decline may result in decreased access to treatment and is an issue that warrants further investigation.

I $\mathrm{n}$ contrast to the coverage offered in other countries with universal health care systems, universal coverage is provided only for physician and hospital services in Canada. ${ }^{1}$ Pharmaceuticals and services such as dental care and vision care are paid through a mix of public and private insurance and out-of-pocket payments. ${ }^{1}$ Approximately $60 \%$ of Canadians hold private insurance for prescription drugs, which is mostly provided by employers to their employees and, in some cases, their retirees. ${ }^{2}$ Other health services are not insured publicly except for certain populations, and the availability of private insurance for these services is unclear.,

The availability of employer-sponsored private health insurance is an important determinant of access to these other types of health care. Older people in particular have been found in various studies to be sensitive to reductions in costs offered through private health insurance..$^{5-7}$ For example, Allin and colleagues found a further reduction of a few dollars through private insurance on copayments of up to $\$ 6.11$ under Ontario's public drug program appeared to incentivize seniors to use certain types of medications. ${ }^{5}$ The higher outof-pocket costs faced by those without such insurance can present a significant barrier to accessing treatment, potentially resulting in poorer health outcomes., ${ }^{3,6-8-12}$ Retirees, who may receive employer coverage as part of a retirement package, may be particularly vulnerable to loss of coverage and increased out-of-pocket costs as they may have limited income flexibility. ${ }^{5,13}$ Thus, it is important to observe any prevailing trends in the coverage of Canadian retirees.

From 1988 to 2015, private health insurance expenditures increased from $\$ 193$ to $\$ 1059$ per capita in Canada. ${ }^{14}$ This increase in costs is being passed onto employers who provide coverage. What remains unclear is how Canadian employers are responding to these changes. Analyses from the United States have found that in response to increasing premiums,

Competing interests: Michael Law has consulted for Health Canada and the Hospital Employees' Union and acted as an expert witness for the Attorney General of Canada. No other competing interests were declared.

This article has been peer reviewed.

Correspondence to: Fiona Chan, fiona.chan@alumni.ubc.ca

CMAJ Open 2019. DOI:10.9778/cmajo.20180067 
steps were taken to limit both the availability and scope of employer coverage. ${ }^{14,15}$ For example, between 1996 and 2000, the proportion of retirees aged 65 to 69 years who had retiree coverage decreased from $46 \%$ to $39 \% .{ }^{15}$ Surveys of employers in Ontario assessing coverage for current and retired employees confirm that employers are becoming less generous. ${ }^{16}$ Although other data also suggest that Canadian employer coverage is becoming less generous,${ }^{17}$ we have limited information on the changes in coverage and the number of people affected, if any. Therefore, we used data from 2 large surveys to investigate the change between 2005 and 2014 in the availability of employer coverage for retirees.

\section{Methods}

\section{Study context}

Public drug coverage schemes for seniors vary widely across provinces. Some provinces (e.g., Ontario, Alberta and the Maritime provinces) have adopted an age-based approach where individuals over the age of 65 years are automatically offered special coverage; other provinces (e.g., British Columbia, Saskatchewan and Manitoba) have adopted an incomebased approach. ${ }^{18,19}$ All of these coverage schemes have annual deductibles — that is, out-of-pocket payments for prescription costs before the start of coverage - and copayments/ coinsurance after coverage starts. ${ }^{18,19}$ Any of these out-ofpocket costs may be reduced by the availability of private insurance, which is most commonly obtained through employers and may include family members as beneficiaries. ${ }^{18}$ Only about $10 \%$ of all private insurance policies are taken out independently. ${ }^{20}$ Allin and colleagues estimated that among Ontario residents over the age of 65 years without an independent private insurance policy, $27 \%$ received private insurance for prescriptions from their current or previous employer in 2005..$^{5}$ Other treatments, such as dental care and vision care, are not covered for seniors in any province except for people with very low incomes. ${ }^{3,4}$ These are funded almost exclusively through private insurance and out-of-pocket payments. ${ }^{3,4}$

\section{Survey data and study design}

This study used data from the Canadian Community Health Survey (CCHS), an ongoing cross-sectional survey conducted by Statistics Canada. The survey sample is derived from a multistage stratified cluster sampling design and is intended to be representative of approximately $97 \%$ of the population aged 12 years and older, with steps taken to account for nonresponse to produce accurate national and regional estimates. Additional information on the sampling and interviewing methods is published elsewhere. ${ }^{21-23}$ Validation steps include comparison of data year to year and by geographical region, as well as external validation by provincial and federal partners to ensure data accuracy. ${ }^{21}$ Before 2005, the survey was conducted every 2 years over a 1 -year period. Since then, the survey has been conducted annually and the results have been released as 2-year cycles to cover the same number of respondents as cycles released before this change.

\section{Study samples}

We used data from the 2005 and 2013-2014 survey cycles. Our study sample was restricted to respondents who resided in Ontario at the time of interview, as it was the only province in which the optional module on health insurance was asked in more than 1 cycle. To capture retirees, we included respondents if they were 75 years of age or older, or if they were aged 65 to 75 years and responded that they had not worked at a job or business at any time in the past 12 months. We excluded people who had immigrated to Canada fewer than 10 years ago to limit the number of people who arrived in Canada after retirement as their inclusion would have inflated the number of people who may potentially have retiree coverage from a Canadian employer. We also excluded those who did not provide valid responses to the questions on employer coverage, job status or immigration status.

\section{Variables for analysis}

Our key variable of interest was whether the person reported having retiree health insurance. This was constructed from self-reported coverage in 4 areas: prescription medications, dental care, eyeglasses and private/semiprivate hospital rooms. We flagged people as having retiree coverage if they reported employer-sponsored insurance for any of these areas. Our explanatory variable was a binary variable denoting survey cycle (2005 or 2013-2014). Our analysis included a range of potential confounders for the relationship between year and employer coverage among retirees, including age, sex, marital status, urban/rural residence, household income, highest education level within the household, self-reported health status and number of reported chronic illnesses (including selfreported asthma, arthritis, hypertension, chronic obstructive pulmonary disease, diabetes, heart disease, previous stroke, bowel disease and mood disorder). The sociodemographic factors were chosen as they are known to influence the likelihood of having employer-sponsored coverage. We chose to control for household income and education within the household as coverage may be available through a spouse. We chose to control for marital status for the same reason. Please refer to Appendix 1 (available at www.cmajopen.ca/content/7/1/E15/ suppl/DC1) for the survey questions.

\section{Statistical analysis}

We modelled the association between survey cycle and reporting having retiree health insurance using a logistic regression model. ${ }^{24}$ On the basis of the results, we also calculated predicted probabilities given individual characteristics and population estimates from 2014. ${ }^{25}$ Population estimates and their variances for all statistical analyses were calculated by applying probability and bootstrap weights provided by Statistics Canada. ${ }^{21}$ The probability weights from the individual survey cycles were adjusted using the pooled approach to produce a single data set to be analyzed. ${ }^{26}$ It was feasible to combine survey cycles using this approach because the questions from which the variables for analysis were derived, survey coverage, and mode of collection had not changed. ${ }^{26}$ 


\section{Sensitivity analysis}

We also performed 2 sensitivity analyses on our logistic regression model. First, we analyzed using reported household incomes instead of income quintiles. We also analyzed the association between survey cycle and each insurance type individually (i.e., insurance for prescription medications, eyeglasses, private/semiprivate hospital rooms and dental care).

\section{Ethics approval}

This study is covered under the publicly available data clause (item 7.10.3) of the University of British Columbia's Policy no. 89: Research Involving Human Participants, which exempts research involving the use of publicly available data protected by law from requiring study-specific ethics approval. ${ }^{27}$

\section{Results}

The response rates were $76 \%$ for the 2005 cycle and $66 \%$ for 2013-2014 for the entire survey. ${ }^{22,23}$ Our final cohort included 6234 respondents from 2005 and 6509 from 2013-2014, with
$51.3 \%$ of the final weighted sample in 2005 and $48.7 \%$ in 2013-2014 (see Figure 1 for derivation). As shown in Table 1, respondents in 2013-2014 had slightly higher education levels and better self-reported health status. However, the number of reported chronic diseases was similar in the 2 cohorts. Notably, respondents in 2013-2014 were comparatively wealthier than the earlier cohort: the percentage of respondents in the lowest quintile of household incomes dropped from $35.2 \%$ in 2005 to $25.2 \%$ in $2013-2014$. The cohorts from the 2 survey cycles were similar in other respects (Table 1). About one-third of respondents reported having retiree health insurance in both cycles: $32.6 \%$ and $33.1 \%$ in the 2005 cycle and 2013-2014 cycles, respectively.

In our prespecified multivariate model, the adjusted odds ratio estimate of receiving retiree health insurance in 2013-14 was 0.87 (95\% confidence interval [CI] 0.77-0.99) compared with 2005 (Table 2). This represents a 13\% decrease in the odds of a retiree receiving coverage. While we found that several other variables were statistically associated with having coverage (Table 2), the decrease in the odds ratio estimates

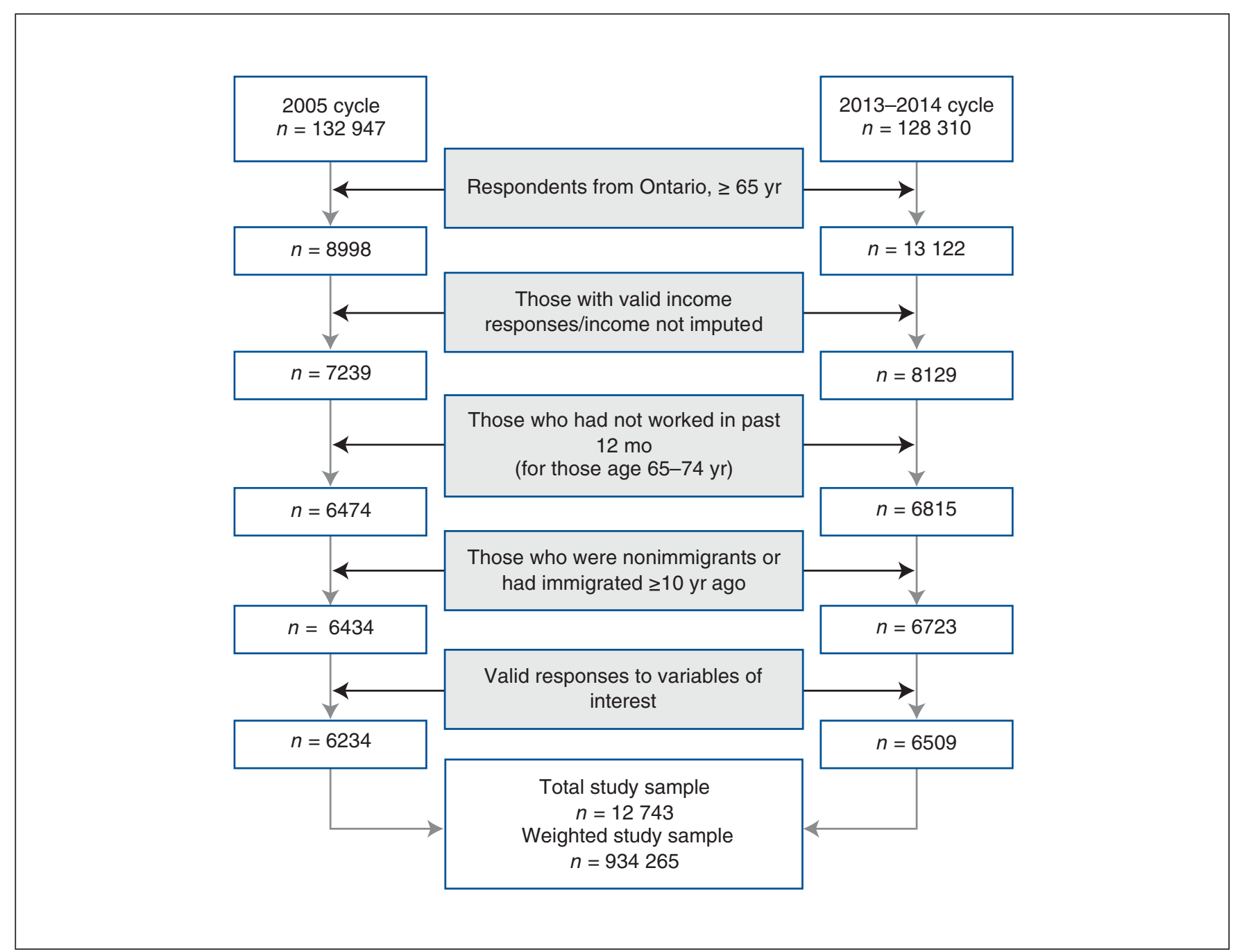

Figure 1: Derivation of study sample from cycle 3.1 (2005 cycle) and the 2013-2014 cycle of the Canadian Community Health Survey, including exclusions because of missing/invalid responses. 
Table 1: Characteristics of study sample, investigating the relationship between availability of retiree health insurance and survey year using data from the combined cycle 3.1 (2005) and the 2013-2014 cycle of the Canadian Community Health Survey

\begin{tabular}{|c|c|c|c|c|c|c|}
\hline \multirow[b]{2}{*}{ Characteristic } & \multicolumn{2}{|c|}{ Total study sample } & \multicolumn{4}{|c|}{ Study sample by survey year } \\
\hline & $\begin{array}{l}\text { Weighted } \\
\text { frequency }\end{array}$ & $\begin{array}{l}\text { Percentage } \\
\quad \pm \text { SE }\end{array}$ & $\begin{array}{l}\text { Weighted } \\
\text { frequency }\end{array}$ & $\begin{array}{c}\text { Percentage } \\
\pm \text { SE }\end{array}$ & $\begin{array}{l}\text { Weighted } \\
\text { frequency }\end{array}$ & $\begin{array}{l}\text { Percentage } \\
\quad \pm \text { SE }\end{array}$ \\
\hline Total study sample & 934265 & 100 & 479192 & $51.3 \pm 0.7$ & 455072 & $48.7 \pm 0.7$ \\
\hline \multicolumn{7}{|l|}{ Insurance availability } \\
\hline Has prescription coverage & 257584 & $27.6 \pm 0.6$ & 129195 & $27.0 \pm 0.4$ & 128388 & $28.2 \pm 0.5$ \\
\hline Has dental coverage & 236215 & $25.3 \pm 0.6$ & 119371 & $24.9 \pm 0.4$ & 116844 & $25.7 \pm 0.5$ \\
\hline Has eyeglasses coverage & 233992 & $23.0 \pm 0.6$ & 117961 & $24.6 \pm 0.4$ & 116031 & $25.5 \pm 0.5$ \\
\hline Has hospital room coverage & 247031 & $26.4 \pm 0.6$ & 133887 & $27.9 \pm 0.5$ & 113143 & $24.9 \pm 0.4$ \\
\hline \multicolumn{7}{|l|}{ Age, yr } \\
\hline$\geq 80$ & 225740 & $24.2 \pm 0.6$ & 114386 & $23.9 \pm 0.5$ & 111354 & $24.5 \pm 0.5$ \\
\hline \multicolumn{7}{|l|}{ Sex } \\
\hline Male & 420238 & $45.0 \pm 0.7$ & 207369 & $43.3 \pm 0.6$ & 212869 & $46.8 \pm 0.7$ \\
\hline Female & 514026 & $55.0 \pm 0.7$ & 271823 & $56.7 \pm 0.6$ & 242203 & $53.2 \pm 0.7$ \\
\hline \multicolumn{7}{|l|}{ Urban/rural dwelling } \\
\hline Rural & 153579 & $16.4 \pm 0.4$ & 68660 & $14.3 \pm 0.3$ & 84919 & $18.7 \pm 0.3$ \\
\hline Urban & 780686 & $83.6 \pm 0.4$ & 410533 & $85.7 \pm 0.7$ & 370153 & $81.3 \pm 0.7$ \\
\hline \multicolumn{7}{|c|}{ Total household income - provincial quintile } \\
\hline Quintile 1 & 283233 & $30.3 \pm 0.7$ & 168447 & $35.2 \pm 0.5$ & 114786 & $25.2 \pm 0.6$ \\
\hline Quintile 2 & 250340 & $26.8 \pm 0.6$ & 131512 & $27.4 \pm 0.5$ & 118828 & $26.1 \pm 0.5$ \\
\hline \multicolumn{7}{|l|}{ No. of chronic illnesses } \\
\hline None & 169573 & $18.2 \pm 0.6$ & 88705 & $18.5 \pm 0.4$ & 80868 & $17.8 \pm 0.4$ \\
\hline 1 or 2 & 547896 & $58.6 \pm 0.7$ & 285002 & $59.5 \pm 0.6$ & 262895 & $57.8 \pm 0.7$ \\
\hline 3 or 4 & 192687 & $20.6 \pm 0.6$ & 94151 & $19.6 \pm 0.4$ & 98536 & $21.7 \pm 0.5$ \\
\hline$\geq 5$ & 24108 & $2.6 \pm 0.2$ & 11335 & $2.4 \pm 0.1$ & 12774 & $2.8 \pm 0.2$ \\
\hline \multicolumn{7}{|l|}{ Marital status } \\
\hline Single/never married & 41097 & $4.4 \pm 0.3$ & 20871 & $4.4 \pm 0.2$ & 20226 & $4.4 \pm 0.2$ \\
\hline Common-law & 21913 & $2.3 \pm 0.3$ & 6364 & $1.3 \pm 0.1$ & 15550 & $3.4 \pm 0.2$ \\
\hline Married & 558578 & $59.8 \pm 0.7$ & 290260 & $60.6 \pm 0.7$ & 268317 & $59.0 \pm 0.7$ \\
\hline Widowed/separated/divorced & 312677 & $33.5 \pm 0.7$ & 161697 & $33.7 \pm 0.5$ & 150980 & $33.2 \pm 0.5$ \\
\hline \multicolumn{7}{|l|}{ Self-reported health status } \\
\hline Excellent & 120993 & $13.0 \pm 0.5$ & 55032 & $11.5 \pm 0.3$ & 65961 & $14.5 \pm 0.4$ \\
\hline Very good & 278512 & $29.8 \pm 0.6$ & 139569 & $29.1 \pm 0.5$ & 139942 & $30.5 \pm 0.5$ \\
\hline Good & 305299 & $32.7 \pm 0.7$ & 158345 & $33.0 \pm 0.5$ & 146954 & $32.3 \pm 0.6$ \\
\hline Fair & 162263 & $17.4 \pm 0.5$ & 89677 & $18.7 \pm 0.4$ & 72586 & $16.0 \pm 0.4$ \\
\hline Poor & 67199 & $7.2 \pm 0.4$ & 36570 & $7.6 \pm 0.3$ & 30629 & $6.7 \pm 0.3$ \\
\hline
\end{tabular}




\begin{tabular}{|c|c|c|}
\hline Variable & $\begin{array}{l}\text { Unadjusted odds } \\
\text { ratio }(95 \% \mathrm{Cl})\end{array}$ & $\begin{array}{c}\text { Adjusted odds ratio } \\
(95 \% \mathrm{Cl})\end{array}$ \\
\hline \multicolumn{3}{|l|}{ Survey year } \\
\hline 2005 cycle (cycle 3.1) & 1 & 1 \\
\hline 2013-2014 cycle & $1.02(0.91-1.15)$ & $0.87(0.77-0.99)$ \\
\hline \multicolumn{3}{|l|}{ Age, yr } \\
\hline $65-69$ & 1 & 1 \\
\hline $70-74$ & $0.87(0.74-1.02)$ & $0.87(0.74-1.02)$ \\
\hline $75-79$ & $0.76(0.65-0.89)$ & $0.80(0.67-0.94)$ \\
\hline$\geq 80$ & $0.72(0.60-0.85)$ & $0.84(0.70-1.00)$ \\
\hline \multicolumn{3}{|l|}{ Sex } \\
\hline Female & 1 & 1 \\
\hline Male & $1.23(1.09-1.38)$ & $1.01(0.89-1.15)$ \\
\hline \multicolumn{3}{|l|}{ Urban/rural dwelling } \\
\hline Rural & 1 & 1 \\
\hline Urban & $1.04(0.91-1.19)$ & $1.36(1.18-1.56)$ \\
\hline \multicolumn{3}{|c|}{ Total household income - provincial quintile } \\
\hline Quintile 1 & 1 & 1 \\
\hline Quintile 2 & $2.88(2.41-3.44)$ & $2.70(2.26-3.25)$ \\
\hline Quintile 3 & $4.36(3.65-5.20)$ & $4.01(3.31-4.86)$ \\
\hline Quintile 4 & $5.73(4.65-7.07)$ & $5.20(4.18-6.48)$ \\
\hline Quintile 5 & $4.99(3.91-6.37)$ & $4.46(3.45-5.76)$ \\
\hline \multicolumn{3}{|c|}{ Highest level of education within household } \\
\hline Did not complete secondary & 1 & 1 \\
\hline Secondary graduate & $1.69(1.42-2.02)$ & $1.31(1.08-1.58)$ \\
\hline At least some postsecondary & $1.98(1.72-2.29)$ & $1.13(0.96-1.32)$ \\
\hline \multicolumn{3}{|l|}{ Number of chronic illness(es) } \\
\hline None & 1 & 1 \\
\hline 1 or 2 & $0.92(0.79-1.07)$ & $1.01(0.86-1.19)$ \\
\hline 3 or 4 & $0.86(0.72-1.03)$ & $1.18(0.96-1.45)$ \\
\hline$\geq 5$ & $0.49(0.34-0.69)$ & $0.73(0.49-1.10)$ \\
\hline \multicolumn{3}{|l|}{ Marital status } \\
\hline Single/never married & 1 & 1 \\
\hline Common-law & $1.82(1.09-3.03)$ & $1.42(0.83-2.43)$ \\
\hline Married & $1.79(1.38-2.32)$ & $1.58(1.19-2.10)$ \\
\hline Widowed/separated/divorced & $0.89(0.68-1.16)$ & $1.04(0.78-1.39)$ \\
\hline \multicolumn{3}{|l|}{ Self-reported health status } \\
\hline Excellent & 1 & 1 \\
\hline Very good & $0.88(0.74-1.05)$ & $0.93(0.77-1.12)$ \\
\hline Good & $0.77(0.64-0.93)$ & $0.89(0.74-1.08)$ \\
\hline Fair & $0.61(0.50-0.74)$ & $0.81(0.65-1.01)$ \\
\hline Poor & $0.48(0.37-0.62)$ & $0.71(0.54-0.93)$ \\
\hline
\end{tabular}


after adjusting for confounding is almost solely attributable to household income. People earning in the second quintile had 2.71 times the odds of receiving coverage compared with people in the first quintile (i.e., those who were poorer) in the adjusted analysis. Those earning in the fourth quintile had the highest odds of having retiree coverage. In other words, despite an increase in the relative income of retirees between the survey waves, there was not a corresponding increase in the availability of retiree coverage.

Using estimates from the multivariate logistic regression, we found that the absolute decrease in predicted probability of receiving retiree health insurance from 2005 to 20132014 ranged from $0.6 \%$ to $3.4 \%$ depending on personal characteristics (Table 3). From 2014 population estimates from Statistics Canada of people over the age of 65 years and given that approximately $16 \%$ of respondents over 65 years of age were excluded from our sample as they were still working, we estimate that approximately 11000 to 62000 Ontario residents were not receiving retiree health insurance. ${ }^{25}$ In both study years, the segment of the population with the lowest predicted probability of receiving retiree coverage was older people, with lower levels of education and income in the household. In contrast, the population with the highest predicted probability of receiving coverage was people with higher levels of education, with a household income in the fourth quintile.

\section{Sensitivity analysis}

We chose to use income quintiles to better compare the odds of having retiree coverage over time between groups on the basis of relative incomes. However, we performed a sensitivity analysis using reported household incomes, categorized in $\$ 20000$ increments up to $\$ 80000$ and more. The adjusted odds ratio using this revised income variable was very similar to the results presented above (adjusted odds

\begin{tabular}{|c|c|c|c|c|}
\hline \multirow[b]{2}{*}{ Characteristics } & \multicolumn{4}{|c|}{$\%$} \\
\hline & 2005 & 2013-2014 & $\begin{array}{l}\text { Absolute } \\
\text { change }\end{array}$ & $\begin{array}{l}\text { Relative } \\
\text { change }\end{array}$ \\
\hline \multicolumn{5}{|c|}{$\begin{array}{l}\text { Age } 65-69 \mathrm{yr} \text {, married, urban dwelling, } 1 \text { or } 2 \text { chronic illnesses, second } \\
\text { income quintile, at least some postsecondary education, very good health }\end{array}$} \\
\hline Male & 52.61 & 49.26 & -3.35 & -6.37 \\
\hline Female & 52.35 & 49 & -3.35 & -6.40 \\
\hline \multicolumn{5}{|c|}{$\begin{array}{l}\text { Age } 65-69 \text { yr, married, urban dwelling, } 1 \text { or } 2 \text { chronic illnesses, fourth income } \\
\text { quintile, some postsecondary education, very good health }\end{array}$} \\
\hline Male & 59.02 & 55.74 & -3.28 & -5.55 \\
\hline Female & 58.77 & 55.48 & -3.28 & -5.59 \\
\hline \multicolumn{5}{|c|}{$\begin{array}{l}\text { Age } 65-69 \text { yr, married, urban dwelling, } 1 \text { or } 2 \text { chronic illnesses, second } \\
\text { income quintile, some postsecondary education, very good health }\end{array}$} \\
\hline Male & 42.84 & 39.6 & -3.25 & -7.58 \\
\hline Female & 42.59 & 39.35 & -3.24 & -7.61 \\
\hline \multicolumn{5}{|c|}{$\begin{array}{l}\text { Age } 65-69 \mathrm{yr} \text {, married, urban dwelling, } 1 \text { or } 2 \text { chronic illnesses, first income } \\
\text { quintile, some postsecondary education, very good health }\end{array}$} \\
\hline Male & 21.68 & 19.49 & -2.19 & -10.10 \\
\hline Female & 21.5 & 19.33 & -2.18 & -10.12 \\
\hline \multicolumn{5}{|c|}{$\begin{array}{l}\text { Age } 70-74 \text { yr, widowed, urban dwelling, } 1 \text { or } 2 \text { chronic illnesses, first income } \\
\text { quintile, secondary school graduate, very good health }\end{array}$} \\
\hline Male & 14.39 & 12.81 & -1.57 & -10.94 \\
\hline Female & 14.26 & 12.7 & -1.56 & -10.96 \\
\hline \multicolumn{5}{|c|}{$\begin{array}{l}\text { Age } 75-79 \text { yr, widowed, rural dwelling, } 1 \text { or } 2 \text { chronic illnesses, first income } \\
\text { quintile, secondary school graduate, very good health }\end{array}$} \\
\hline Male & 11.03 & 9.78 & -1.25 & -11.32 \\
\hline Female & 10.92 & 9.68 & -1.24 & -11.33 \\
\hline \multicolumn{5}{|c|}{$\begin{array}{l}\text { Age } \geq 80 \text { yr, never married, rural dwelling, } \geq 5 \text { chronic illnesses, first income } \\
\text { quintile, did not complete secondary school, poor health }\end{array}$} \\
\hline Male & 5.02 & 4.42 & -0.60 & -12.00 \\
\hline Female & 4.97 & 4.38 & -0.60 & -12.00 \\
\hline
\end{tabular}


ratio $0.86,95 \%$ CI $0.74-0.98$ ). We also analyzed each insurance type individually to ensure that 1 type did not bias our original estimate using our aggregated variable. These analyses yielded odds ratio point estimates similar to our original estimate, but with wider confidence intervals (data not shown).

\section{Interpretation}

Employer-sponsored health insurance remains an important mechanism through which many Canadians, including retirees, access important forms of health care. We found that the adjusted rates of employer coverage for retirees declined over time. These findings suggest that, much like in the United States, ${ }^{15,28}$ the odds of a retired employee receiving coverage have decreased for comparable populations over the past decade in Ontario. From population estimates, up to 62000 Ontario residents over the age of 65 years were potentially affected by this trend. The public health implications of this finding may be important, as Canadians often rely on private insurance provided by employers to afford health treatments that are not publicly covered. ${ }^{3,5,6}$

The results of this study explain some of the observations in prior research. Out-of-pocket health-related expenses from 1998 to 2009 increased substantially, with premiums for private health insurance (including employer coverage) being prominent expenses..$^{29}$ Additionally, a growing proportion of Canadian households are spending more than $10 \%$ of their income on health expenses. ${ }^{29}$ Our results also corroborate previous industry surveys conducted in the province, which found that many employers had plans to reduce the coverage they provide. ${ }^{16}$ As private insurance helps offset the out-ofpocket costs for treatments, ${ }^{3,5,6}$ the decrease in coverage availability observed in our study may be linked to evidence of increased expenditures by Canadian households to obtain items such as dental services and prescription drugs. ${ }^{29}$ Taken together, current evidence suggests that private insurance plans, most of which are employer sponsored, are becoming more expensive for Canadians and provide less extensive coverage, with coverage availability also being negatively affected. Additionally, if the changes observed in our study are occuring in other provinces, they may affect access to medicines to an even greater degree than in Ontario, as Ontario seniors receive generous public subsidies for prescription drugs under the Ontario Drug Benefits program. ${ }^{30}$

As previously discussed, much of our finding is attributable to changes in the household income structure of retirees. Indeed, in examining the makeup of our cohort in the 2 time periods, respondents in 2013-2014 reported income that put them in a higher quintile (relative to the entire province) than those in 2005. It has been found previously that private insurance availability (through an employer or otherwise) is associated with one's income. ${ }^{5,8,9,31}$ Thus, with more people reporting higher household incomes, it may appear that retiree coverage availability was maintained between 2005 and 2013-2014. However, as the adjusted analysis showed, the odds of having retiree health insurance in fact decreased over this period, after taking into account income and other confounders.

\section{Limitations}

Our study has some limitations. First, the data are derived from 2 cross-sectional surveys and may be subject to recall bias. However, it seems unlikely that knowledge about employer coverage would have been different among the 2 cohorts. Second, we were not able to assess historical employment status and it is possible that respondents did not have retiree coverage because they were not employed previously. Owing to the survey structure, we also had to assume that people over the age of 75 years were not employed at the time of the survey. Lastly, we were only able to examine the association between receiving coverage and time by using 2 survey cycles. The results may oversimplify how retiree coverage has changed over time, especially given prior research that observed extensive use of costcontrolling mechanisms among private insurance plans generally (e.g., increased premiums, cost-sharing and deductibles). ${ }^{17}$ However, given that discontinuing coverage is the most severe form of cost control, we feel these results provide a potentially important body of preliminary evidence that warrants further investigation. Future studies should investigate the proportion of retirees experiencing increased policy premiums or increased cost-sharing for treatments. ${ }^{17}$

\section{Conclusion}

The decrease in retiree health insurance availability is a potential public health issue, as cost-related nonadherence to medically necessary treatments may subsequently increase adverse health outcomes and health resource utilization. While older Canadians currently have among the lowest rates of problems with drug affordability in Canada, ${ }^{32}$ this might change if coverage availability declines. Further, as costs continue to rise, the decline in the availability of benefits may accelerate. This potential burden on the public system may provide impetus for policy-makers to further study other important employer health insurance trends in Canada such that appropriate policy action may be taken to maintain access to essential treatments in this population.

\section{References}

1. Law MR, Kratzer J, Dhalla IA. The increasing inefficiency of private health insurance in Canada. CMA7 2014;186:E470-4.

2. Allin S, Hurley J. Inequity in publicly funded physician care: What is the role of private prescription drug insurance? Health Econ 2009;18:1218-32.

3. Quiñonez C, Figueiredo R. Sorry doctor, I can't afford the root canal, I have a job: Canadian dental care policy and the working poor. Can 7 Public Health 2010;101:481-5.

4. Ngo G, Trope G, Buys Y, et al. Significant disparities in eyeglass insurance coverage in Canada. Can 7 Ophthalmol 2018;53:260-5.

5. Allin S, Law MR, Laporte A. How does complementary private prescription drug insurance coverage affect seniors' use of publicly funded medications? Health Policy 2013;110:147-55.

6. Kratzer J, Cheng L, Allin S, et al. The impact of private insurance coverage on prescription drug use in Ontario, Canada. Healthc Policy 2015;10:62-74.

7. Devlin RA, Sarma S, Zhang Q. The role of supplemental coverage in a universal health insurance system: some Canadian evidence. Health Policy 2011;100:81-90.

8. Ramraj C, Sadeghi L, Lawrence HP, et al. Is accessing dental care becoming more difficult? Evidence from Canada's middle-income population. PLoS One 2013;8:e57377.

9. Locker D, Maggirias J, Quiñonez C. Income, dental insurance coverage, and financial barriers to dental care among Canadian adults. 7 Public Health Dent 2011;71:327-34.

10. Dormuth CR, Maclure M, Glynn RJ, et al. Emergency hospital admissions after income-based deductibles and prescription copayments in older users of inhaled medications. Clin Ther 2008;30:1038-50. 
11. Tamblyn R, Laprise R, Hanley J, et al. Adverse events associated with prescription drug cost-sharing among poor and elderly persons. FAMA 2001;285:421-9.

12. Goldman DP, Joyce G, Zheng Y. Prescription drug cost sharing: associations with medication and medical utilization and spending and health. $7 A M A$ 2007;298:61-9.

13. Bull D. The end of retiree benefits? Benefits Canada 2015 Oct. 27.

14. National health expenditure trends, 1975 to 2017. Ottawa: Canadian Institute for Health Information; 2017. Available: https://secure.cihi.ca/free_products/ nhex2017-trends-report-en.pdf (accessed 2018 Apr. 26).

15. Stuart B, Singhal PK, Fahlman C, et al. Employer-sponsored health insurance and prescription drug coverage for new retirees: dramatic declines in five years. Health Aff (Project Hope). 2003;Suppl Web:W3-334-41.

16. West D. Cost trends in health benefits for Ontario businesses: analysis for discussion. Toronto: Mercer (Canada); 2011.

17. Kratzer J, McGrail KM, Strumpf E, et al. Cost-control mechanisms in Canadian private drug plans. Healthc Policy 2013;9:35-43.

18. Morgan SG, Daw JR, Law MR. Rethinking pharmacare in Canada. Toronto: CD Howe Institute; 2013.

19. Morgan SG, Daw JR. Canadian pharmacare: looking back, looking forward. Healthc Policy 2012;8:14-23.

20. Canadian life and health insurance facts 2017. Ottawa: Canadian Life and Health Insurance Association; 2017. Available: http://clhia.uberflip.com/i/ 878840-canadian-life-and-health-insurance-facts-2017/17? (accessed 2018 Jan. 23).

21. Canadian Community Health Survey (CCHS). Definitions, data sources and methods. Ottawa: Statistics Canada; 2016. Available: http://www23.statcan.gc.ca/imdb/ p2SV.pl? Function=getSurvey\&SDDS=3226 (accessed 2016 Oct. 14).

22. Canadian Community Health Survey (CCHS) Cycle 3.1 (2005): public use microdata file (PUMF) user guide. Ottawa: Statistics Canada; 2006.

23. Canadian Community Health Survey (CCHS) annual component: user guide 2014 and 2013-2014 microdata files. Ottawa: Statistics Canada; 2015.

24. Vittinghoff E, Glidden D, Shiboski S, et al. Logistic regression. In: Regression methods in biostatistics. 2nd ed. New York: Springer New York; 2012:139-202.

25. CANSIM - 051-0001 - Estimates of population, by age group and sex for fuly 1, Canada, provinces and territories. CANSIM (database). Ottawa: Statistics Canada; 2016. Available: http://www5.statcan.gc.ca/cansim/a47 (accessed 2017 Aug. 9).

26. Thomas S, Wannell B. Combining cycles of the Canadian Community Health Survey. Health Rep 2009;20:53-8.

27. Policy \#89: Research involving human participants. Vancouver: The University of British Columbia Board of Governors; 2016. Available: http://universitycounsel. ubc.ca/files/2012/06/policy89.pdf (accessed 2016 Oct. 18).
28. Buchmueller TC, Monheit AC. Employer-sponsored health insurance and the promise of health insurance reform. Inquiry 2009;46:187-202.

29. Law MR, Daw JR, Cheng L, et al. Growth in private payments for health care by Canadian households. Health Policy 2013;110:141-6.

30. Get coverage for prescription drugs. Government of Ontario. Available: www.ontario.ca/page/get-coverage-prescription-drugs (accessed 2017 Aug. $15)$.

31. Dewa CS, Hoch J, Steele L. Prescription drug benefits and Canada's uninsured. Int 7 Law Psychiatry 2005;28:496-513.

32. Law MR, Cheng L, Kolhatkar A, et al. The consequences of patient charges for prescription drugs in Canada: a cross-sectional survey. CMA7 Open 2018; 6:E63-70

Affiliations: Centre for Health Services and Policy Research, School of Population and Public Health (Chan, McGrail, Law), University of British Columbia, Vancouver, BC; Department of Medicine (Majumdar), University of Alberta, Edmonton, Alta.

Contributors: Fiona Chan developed the research question and the empirical approach, analyzed the data and drafted all material related to the employer health insurance analysis. Michael Law, Kimberlyn McGrail and Sumit Majumdar provided guidance throughout the research process. They contributed substantially to the conception and design of the analysis and the interpretation of the data and revised the manuscript critically for important intellectual content. All authors gave final approval of the version to be published and agreed to be accountable for all aspects of the work.

Acknowledgements: This analysis was funded by a Foundation Scheme Grant from the Canadian Institutes of Health Research (FDN-148412, principal investigator: Michael Law). Dr. Law received salary support through a Canada Research Chair in Access to Medicines and a Michael Smith Foundation for Health Research Scholar Award. The authors would also like to thank Dr. Mieke Koehoorn for her contribution to this research.

Supplemental information: For reviewer comments and the original submission of this manuscript, please see www.cmajopen.ca/content/7/1/ E15/suppl/DC1. 